\title{
A comparison of foam stability at varying salinities and surfactant concentrations using bulk foam tests and sandpack flooding
}

\author{
Negar Hadian Nasr ${ }^{1}\left[\right.$. Syed M. Mahmood ${ }^{1} \cdot$ Saeed Akbari ${ }^{1} \cdot$ Hamed Hematpur ${ }^{2}$
}

Received: 18 October 2018 / Accepted: 28 May 2019 / Published online: 6 June 2019

(c) The Author(s) 2019

\begin{abstract}
Two conventional approaches for foam screening are core/sandpack flooding and bulk foam stability tests. The former is more accurate, but requires expensive equipment and long test duration. For initial screening, the faster and cost-effective bulk foam stability tests are used to narrow down the selection to a few surfactants, which are then further tested using corefloods/sandpacks. The bulk foam stability tests have been historically used for surfactant selection at a fixed salinity and fixed surfactant concentration. The foam generated in bulk foam stability test was observed to be quite homogeneous, whereas foam generated through porous media is more heterogeneous; hence, a modification to the bulk foam test was made in that a small quantity of quartz river sand was placed at the bottom of the test tube for generating foam that simulates porous media. To evaluate the use of bulk foam and modified bulk foam stability tests for screening and optimizing salinity and surfactant concentrations, sandpack flooding tests were conducted at a range of salinities, and surfactant concentrations and results were compared. Bulk foam stability tests results were found to be compatible with sandpack results for surfactant concentration optimizations, but showed significant deviation for salinity optimization. The modified bulk foam stability tests, however, showed better agreement with sandpack results in both salinity and surfactant concentration tests.
\end{abstract}

Keywords Foam $\cdot$ Bulk foam stability test $\cdot$ Modified bulk foam stability test $\cdot$ Sandpack flooding

\section{Introduction}

Water-alternating-gas (WAG) has been used as an improved oil recovery technique through decades to displace oil and to maintain reservoir pressure (Akbari et al. 2017a; b). A common problem in this process is unstable displacement because the viscosity of the injected gas is order of magnitude lower than the reservoir oil and water, which causes gas to form fingers and channels (Namani et al. 2012). A recent improvement to this technique is surfactant-alternating-gas (SAG) in which dilute concentrations of foaming surfactant solutions are added to the injected water. The viscosity of gas injected in subsequent cycle is significantly improved because of foam generation, which improves front stability

Negar Hadian Nasr

negar.hadian@gmail.com

1 Department of Petroleum Engineering, University Teknologi Petronas, Seri Iskandar, Malaysia

2 Research Institute of Petroleum Industry, Tehran, Iran and thus oil production (Bond and Holbrook 1958; Apaydin and Kovscek 2001).

Undoubtedly, the technique has shown great promise, yet it has not been as broadly applied as it could have been. The problem is that in situ foam behavior is complex and its optimization and predictability for field application are still uncertain. Questions often arise such as how to select a winning surfactant and its optimal concentration (Apaydin and Kovscek 2001; Fukami and Chen 1998). There are a variety of commercially available surfactants claiming to be the best performer. However, no single surfactant can be the best for all reservoirs as the conditions vary.

From the earlier studies, it appears that the most reliable way to determine the performance of a foaming surfactant under various operating conditions is the laboratory coreflooding experiments under simulated reservoir conditions (Farajzadeh et al. 2010; Kristiansen and Holt 1992; Mannhardt et al. 2000; Andrianov et al. 2012) However, the coreflooding experiments are time-consuming and expensive, especially if the choice of surfactant has to be made from a large number of candidate surfactants. 
In practice, the initial screening is performed using "bulk foam stability test," referred to in the literature by a variety of names such as "static test" or "column test" as well. The stability of foam is measured in terms of "half-life," i.e., the time it takes for generated foam to collapse to half of its initial height (Aronson et al. 1994; Khatib et al. 1988) These tests are faster and cheaper requiring only commonly available glassware in the laboratory, though commercially available automated systems with imaging capabilities such as "FoamScan" can be used if available. However, the bulk foam stability test results are later supplanted with coreflood tests or sandpack flooding tests for final selection of a surfactant as well as to optimize operating parameters such as injection rate, surfactant concentration, salinity and the best mode of injection (Mannhardt et al. 2000; Falls et al. 1989).

Though widely used, the validity of bulk foam stability tests continues to be challenged because there are significant physical differences in the decay behavior between foam in porous media and the bulk foam (Aronson et al. 1994). A bulk foam primarily decays due to gravity drainage, coalescence and coarsening due to gas diffusion, with the latter two mechanisms causing an increase in the average bubble size and eventually turning into a dry bulk foam of a polyhedral structure (Mannhardt et al. 2000; Falls et al. 1989).

The foam in a porous medium, on the other hand, has a lesser degree of freedom and is unable to form a polyhedral structure; it is instead a dispersion of gas in the liquid phase in the form of ganglia separated by foam lamellae. Also, capillarity and saturation play a pivotal role in the performance of in situ foam. In this study, it was hypothesized that the presence of sand, at least during foam generation, is likely to yield more realistic results. Therefore, a modified version of the bulk foam stability test was introduced that contained sand at the bottom of the cylinder through which $\mathrm{N}_{2}$ was percolated to generate foam.

There are various studies had been carried out to test the foam stability at the presence and absence of oil under different conditions for different parameters. Osei-bonsu et al. (2015) tested the foam stability using bulk foam stability test for four different surfactants (sodium dodecyl sulfate, cocamidopropyl betaine, CocoSDS and Triton X100. They made by mixing 1:1 ratio of cocamidopropyl betaine and sodium dodecyl sulfate) in the presence and absence of three iso-paraffin oils. In the absence of oil, cocobetaine was shown the highest stability while CocoSDS (the surfactant mixture) was the best performing surfactant in the presence of oil. This is due to the presence of betaine in the mixture which theoretically increased the critical capillary pressure of the foam films. Other reason is because of the high viscosity of CocoSDS which influenced its stability by reducing the time of liquid drainage from the Plateau borders and causing higher resistance to film thinning. He concluded that foam stability in the presence and absence of the oil is completely different and the foam stability in the presence of the oil is largely depend on the surfactant type and oil properties. He also mentioned that small chain hydrocarbons with lower density and viscosity are more detrimental to the longevity of foams than long chain hydrocarbons (Oseibonsu et al. 2015).

Vikingstad and Aarra (2009) observed that the foam stability and strength were similar in both bulk foam stability tests and coreflood stability tests in oil-free conditions. Also, Jones et al. (2015) suggested using bulk foam stability tests as a proxy to coreflood stability tests for screening foaming surfactants. Even though some studies showed positive correlation under oil-free conditions, they failed to show a consistent correlation in the presence of oil (Mannhardt et al. 2000; Jones et al. 2015 Vikingstad and Aarra 2009). Whereas van der Bent (2014) concluded that bulk foam stability tests could be used to infer surfactant performance in coreflood in the absence of oil, however, he could not find a good correlation between the two methods in the presence of oil (van der Bent 2014; Hadian et al. 2019). In addition, foam decay behavior significantly varies between oil-free and in the presence of oil conditions and the oil-surfactant solution IFT will always be lower than the gas-surfactant solution IFT causing a faster rate of foam decay in the presence of oil (Huh 1979; Torrealba and Johns 2017).

Many more studies are needed in this area to get a better understanding of the efficacy of bulk foam stability tests in comparison with the dynamic core/sandpack floods. This study investigates the ability of bulk foam stability tests to identify optimum surfactant concentration and optimum salinity vis-a-vis sandpack floods in the absence of oil for a new mixed anionic and amphoteric surfactant.

\section{Materials and methodology}

A brief description of the brine, surfactant, sand and their processing technique is provided in this section.

\section{Brine preparation}

Three different synthetic brine solutions of $0.5,2.0$ and 3.5 wt $\%$ salinity were used for the effect of salinity and surfactant concentration tests. The high-purity chemical grade salt was provided by Merck Company with properties listed in Table 1.

\section{Surfactants}

A mixed anionic and amphoteric surfactant called MFOMAX was used in this study. It is a proprietary surfactant which was provided by PETRONAS Research Sdn Bhd 
Table 1 Properties of sodium chloride

\begin{tabular}{lllll}
\hline Description & Formula & $\begin{array}{l}\text { Molar mass } \\
(\mathrm{g} / \mathrm{mol})\end{array}$ & $\begin{array}{l}\text { Melting point } \\
\left({ }^{\circ} \mathrm{C}\right)\end{array}$ & $\begin{array}{l}\text { Density }(\mathrm{g} / \\
\left.\mathrm{cm}^{3}\right)\end{array}$ \\
\hline $\begin{array}{c}\text { Sodium } \\
\text { chloride }\end{array}$ & $\mathrm{NaCl}$ & 58.44 & 801 & 2.17 \\
\hline
\end{tabular}

(PRSB). The properties of MFOMAX are shown in Table 2.

\section{Gas for foaming}

The foam was generated using pure nitrogen $\left(\mathrm{N}_{2}\right)$ for this study. Though $\mathrm{CO}_{2}$ has been used in some previous research studies, it was avoided due to significant solubility in water and corrosiveness. The literature suggests that stronger foam can be generated with $\mathrm{N}_{2}$ as compared to $\mathrm{CO}_{2}$ and it is more compatible with wider variety of surfactants (Farajzadeh et al. 2009).

\section{Sand used for packing sandpack for flooding tests}

The sand-holder rubber sleeve of the sandpack flooding system was packed with quartz river sand with properites as listed in Table 3. Since no adhesive or binding agent was used, the sand in the sandpack stayed unconsolidated rendering it to be highly permeable and porous.

The high permeability and porosity of the sandpack were desirable in terms of foam generation capability inside porous media (Bergeron et al. 1993), as well as to minimize the capillary end effects which could significantly affect the flooding results since foaming is highly sensitive to foam quality (gas-to-liquid fraction).

Table 2 Properties of surfactant used in this study

\begin{tabular}{ll}
\hline Name & MFOMAX \\
\hline Description & $\begin{array}{c}\text { Mixed anionic } \\
\text { and amphoteric } \\
\text { surfactant }\end{array}$ \\
Type & Mixed \\
Physical state & Liquid \\
Molecular weight average $\mathrm{g} / \mathrm{mol}$ & Proprietary \\
$\%$ Activity & $20 \%$ \\
pH & $6-6.5$ \\
Concentration tested $(\mathrm{wt} \%)$ & $0.1,0.5,1.0$ \\
Salinities tested $(\mathrm{wt} \%)$ & $0.5,2,3.5$ \\
\hline
\end{tabular}

Table 3 Sandpack properties

\begin{tabular}{ll}
\hline Sandpack length & 600 \\
Sandpack diameter (mm) & 39 \\
Total sand weight (grams) & 1297 \\
Pore volume by gravimetric (cc) & 204 \\
Pore volume by volumetric (cc) & 212 \\
Avg. pore volume (cc) & 208 \\
Porosity (\%) & 29 \\
Absolute permeability (md) & 1791 \\
Residual water saturation using Timur's correlation & $17 \%$ \\
\hline
\end{tabular}

\section{Brine and surfactant solution preparation}

The stock solutions of 100,000 ppm brine and 50,000 ppm surfactant were prepared using $\mathrm{NaCl}$ and MFOMAX, respectively. To prepare a desired solution of given salinity and surfactant concentration, the two stock solutions (brine and surfactant) were mixed in proper ratio and the mixture was then diluted by adding calculated volumes of distilled water to achieve the desired solutions. Three solutions of $0.5 \mathrm{wt} \%$ MFOMAX concentration were prepared at $0.5,2$ and $3.5 \mathrm{wt} \%$ salinities for the effect of salinity tests, and another three solutions of $0.1,0.5$ and $1 \mathrm{wt} \%$ MFOMAX concentrations were prepared at fixed salinity of $2.0 \mathrm{wt} \%$ for the effect of surfactant concentration tests.

\section{Bulk foam stability tests}

The test was performed by adding $50 \mathrm{ml}$ of the surfactant solution into a clean 1000-ml graduated cylinder of $6 \mathrm{~cm}$ diameter, and a plastic tube was inserted to almost touch the bottom as shown in Fig. 1a. $\mathrm{N}_{2}$ gas from a cylinder was then injected at a rate of $30 \mathrm{cc} / \mathrm{min}$ (rate controlled by the gas regulator) through the plastic tube. As the foam generation would start, the height of the foam column would start increasing. When the rise in foam height stopped due to reaching equilibrium (new bubble generation equaled bubble collapse), $\mathrm{N}_{2}$ injection was stopped, the stopwatch was started to begin counting the lapse time, photographs were taken intermittently, and the height of the foam column was noted periodically. This process continued for about 1 day after which the test was terminated.

In the modified bulk foam stability test, $20 \mathrm{~g}$ of quartz river sand of dual grain sizes (212 and 425 microns) was placed at the bottom of the cylinders as shown in Fig. $1 \mathrm{~b}$. Gas for foaming was introduced through the sand layer which acted as foam pre-generator with the ability to generate diverse-sized foam bubbles. 


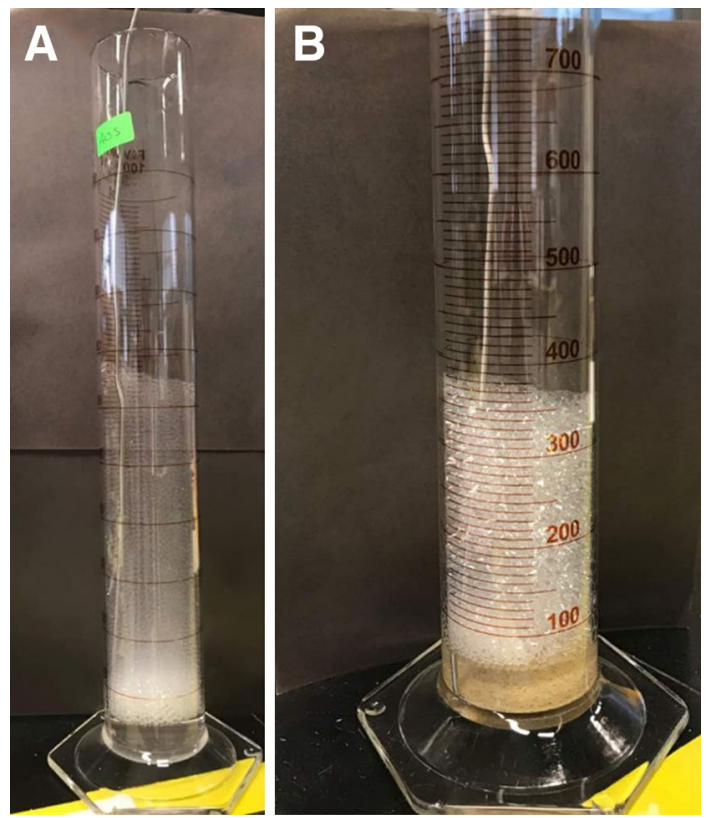

Fig. 1 Graduated cylinder used in bulk foam stability tests: a without sand and $\mathbf{b}$ with sand

Other than the foam generation through the foam, other operational details of both are the same except that a shorter duration of $5 \frac{1}{2} \mathrm{~h}$ was deemed adequate for the modified test to complete.
Figure 1 shows the graduated cylinders used in the bulk foam stability tests with a stainless steel tube inserted to the base.

\section{Sandpack foam flooding system}

Figure 2 shows the schematic diagram of the sandpack foam flooding system.

The sandpack foam flooding system was designed and custom-made in-house to incorporate specific features that were not found in commercially available systems at the time (Farzaneh and Sohrabi 2013; Fergui et al. 1998; Ma et al. 2013). It contained unconsolidated sand as porous medium in a 600-mm-long and 39-mm-diameter coreholder. The extended length is useful for avoiding capillary end effects that could be detrimental to foaming. The advancement of foam flood was monitored via a series of equispaced autoswitchable dual-range pressure and resistivity gauges.

The digital weighing scale and mass flow controller were installed after the liquid accumulator and gas cylinder to control the rate and total amount of liquid and gas to be injected into the sandpack. The saturation changes in the sandpack were computed by material balance.

The pre-test steps required were to set the injection and back pressures to 40 psig and 20 psig, respectively. The sandpack system was cleaned and saturated with brine followed by injection of enough pore volume of surfactant

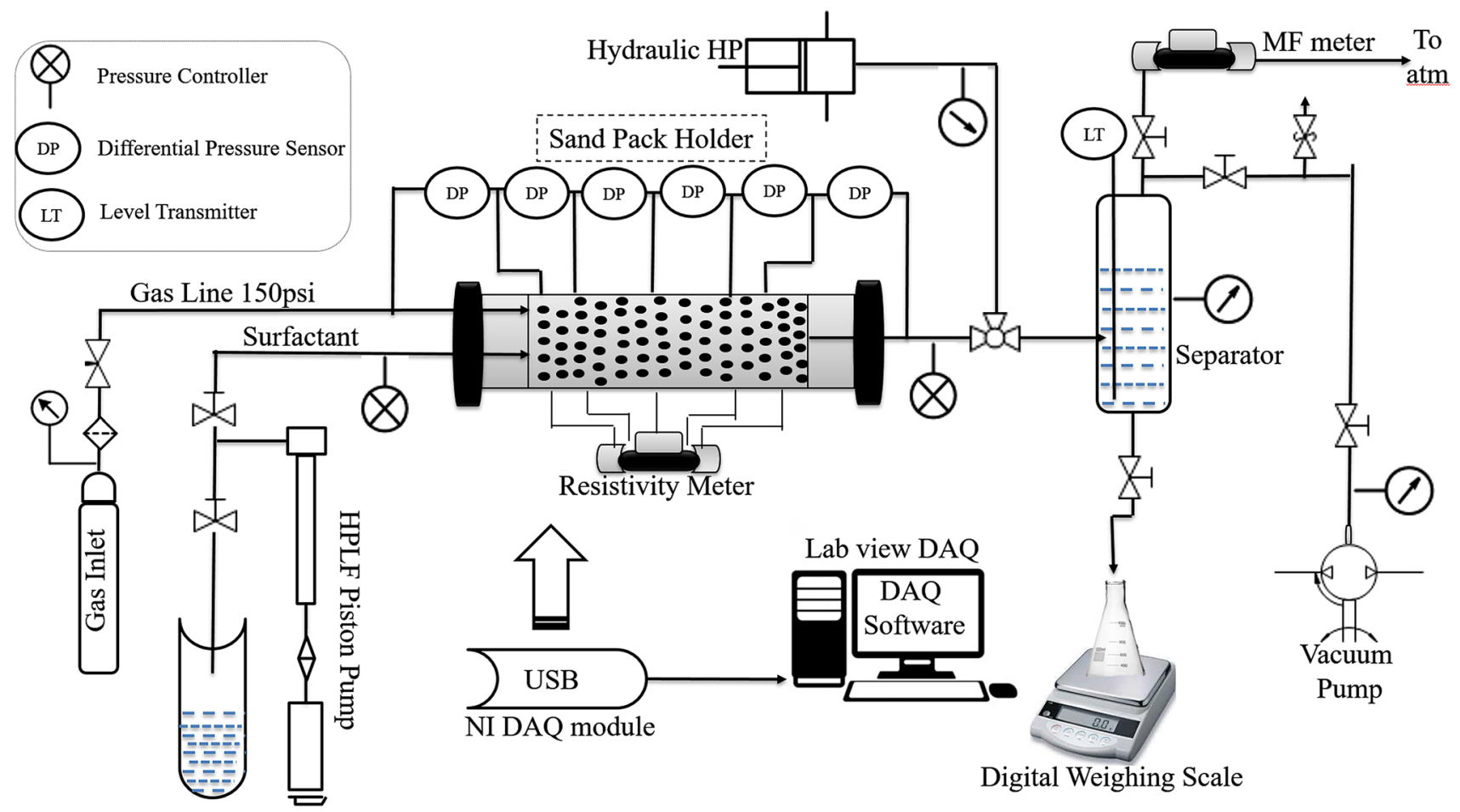

Fig. 2 Sandpack foam flooding system 
solution to overcome adsorption and removal of all movable brine.

Each test began by injecting $\mathrm{N}_{2}$ at $6 \mathrm{cc} / \mathrm{min}$. The pressure drops at various locations were noted from the 12 DPs (differential pressure transmitters). Six of the DPs had a higher pressure range but with a lesser resolution/accuracy, while the remaining six were a lower range with higher resolution/ accuracy. The low- and high-range DPs were located parallel to each other and were installed at six equidistant locations throughout the sandpack. This dual-range arrangement was necessary for accuracy as well as to protect the DPs from over pressurization. The pressure drops for gas and brine were very low (in tenths of a psi), whereas the pressure drop during foam generation could be much higher (up to 100 psi).

\section{Results and discussion}

Two series of experiments were performed to compare the screening effectiveness of bulk foam stability test and modified bulk foam stability test against the sandpack results. The first series compared the screening of the effect of salinity, whereas the second series compared the surfactant concentration.

\section{Effect of salinity}

This section presents the sandpack flooding tests results, followed by bulk foam stability tests and modified bulk foam stability tests for screening the salinity effect.

\section{Sandpack flooding tests}

These tests involved unsteady-state surfactant solution drainage by $\mathrm{N}_{2}$ injection. Before each test, the sandpack was cleaned, dried, evacuated and fully saturated with brine, which was then displaced by MFOMAX solution of $0.5 \mathrm{wt} \%$ concentration of variable salinities. The gas injection was then started, and pressure drop was noted from the beginning of gas injection till the end of the test. The operating conditions are shown in Table 4.

The sandpack flooding results are presented in Fig. 3, which shows that the foaming started earliest in case of 3.5 wt\% salinity after only $0.5 \mathrm{PV}$ of $\mathrm{N}_{2}$ injection. In case of the other two salinity concentrations, the onset of foaming was delayed till 1.25 PV injection.

The peak pressure drop (DP) was 5.7 psig in cases of $3.5 \mathrm{wt} \%$ and $5.5 \mathrm{psig}$ for $2.0 \mathrm{wt} \%$ salinities, whereas it only reached up to $3.5 \mathrm{psig}$ in case of $0.5 \mathrm{wt} \%$ salinity. The collapse of foaming started at $2.4 \mathrm{PV}$ in cases of $3.5 \mathrm{wt} \%$ and $2.0 \mathrm{wt} \%$ salinities, whereas collapse was much earlier after only $1.5 \mathrm{PV}$ of injection in case of $0.5 \mathrm{wt} \%$. This behavior is
Table 4 Operating conditions of sandpack flood run

\begin{tabular}{ll}
\hline Parameters & Sandpack flood \\
\hline Porosity & $29 \%$ \\
Permeability by liquid (md) & 1791.35 \\
Confining pressure (psig) & 150 \\
Back pressure (psig) & 20 \\
Injection rate (cc/min) & 6 \\
Surfactant solution salinity & $0.5,2$ and $3.5 \mathrm{wt} \%$ \\
Surfactant concentration & $0.5 \mathrm{wt} \%$ \\
\hline
\end{tabular}

consistent with previous observations where foam stability was found to be sensitive to salinity at certain ranges, though increasing salinity generally improved the foam stability if it is under the fix range (Liu et al. 2005). The pressure drop (DP) at the valley (lowest observed DP) was 0.9 psig for all three salinities tested.

Overall, the behavior of $3.5 \mathrm{wt} \%$ salinity was quite similar to $2.0 \mathrm{wt} \%$ salinity except that lower salinity caused a delay of foam generation by $0.5 \mathrm{PV}$, but it lasted longer by the same pore volume injection; hence, the foaming performance was shifted by $0.5 \mathrm{PV}$ of injection. However, the behavior of $0.5 \mathrm{wt} \%$ salinity test was different, and it did not perform that well as compared to the other two.

The anionic surfactant is negatively charged, and increasing the salinity will increase $\mathrm{Cl}^{-}$(which carries the negative ions) and thus increase the repulsion forces in the solution weakening the foam lamellae and lowering the foam stability. The same behavior has been seen by Hirasaki Group. However, the reduction in foam stability with an increase in ionic strength is not as significant in oil-free condition and it highly depends on type of surfactant and its structure (Agneta et al. 2019; Varade and Ghosh 2017; Dong et al. 2018). In addition to anionic surfactant, MFOMAX also contains polymer and betaine which reduce the anionicity feature of the surfactant with an increase in salinity up to certain range resulting in stronger lamellae and better foam stability. Same observations have been reported for zwitterionic surfactants in which an increase in the salinity decreased the foam collapse rate and resulted in better foam stability.

This case result may vary in the presence of oil, as anionic surfactants can change their preferential affinity to either water or oil by changes in salinity and it is related to the free energy transfer from one phase to the other. The HLD (hydrophilic-lipophilic deviation) concept can be used to understand the preferential affinity of surfactant to oil and water and its deviation from the optimum formulation (Torrealba et al. 2018; Salager et al. 2000).

In summary, the sandpack flood test revealed that the 3.5 wt $\%$ salinity performed best, followed closely by $2.0 \mathrm{wt} \%$ salinity, and the lowest performer was the $0.5 \mathrm{wt} \%$ salinity 
Fig. 3 Determination of salinity effect by using the unsteadystate surfactant drainage by gas flooding in the sandpack

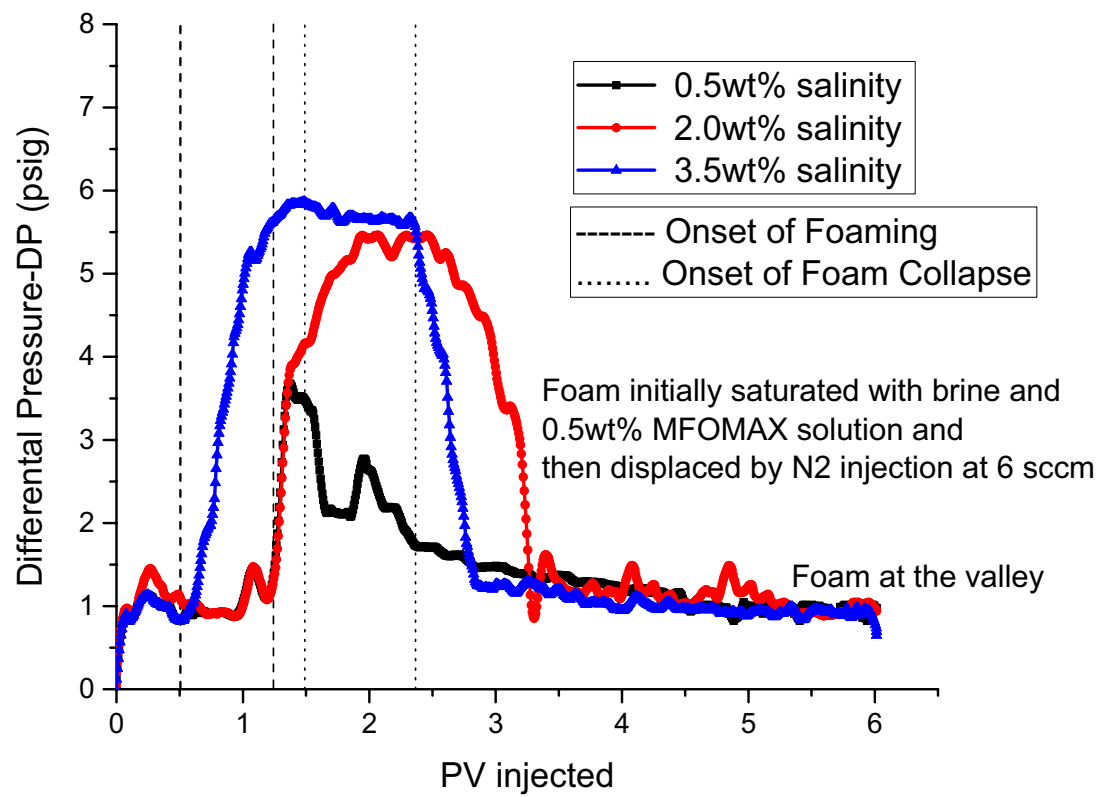

Table 5 Summary of sandpack flood result observations for the effect of salinity

\begin{tabular}{llll}
\hline Salinity & $3.5 \mathrm{wt} \%$ & $2.0 \mathrm{wt} \%$ & $0.5 \mathrm{wt} \%$ \\
\hline Onset of foaming & $0.5 \mathrm{PV}$ & $1.25 \mathrm{PV}$ & $1.25 \mathrm{PV}$ \\
Peak DP & $5.7 \mathrm{psig}$ & $5.5 \mathrm{psig}$ & $3.5 \mathrm{psig}$ \\
Onset of foam collapse & $2.4 \mathrm{PV}$ & $2.4 \mathrm{PV}$ & $1.5 \mathrm{PV}$ \\
$\begin{array}{l}\text { Total PV which DP drop } \\
\quad 0.4 \mathrm{PV}\end{array}$ & $0.9 \mathrm{PV}$ & $2.1 \mathrm{PV}$ \\
$\quad$ from peak to valley & & & \\
DP at the valley & $0.9 \mathrm{psig}$ & $0.9 \mathrm{psig}$ & $0.9 \mathrm{psig}$ \\
\hline
\end{tabular}

test at oil-free condition. The above observations from Fig. 3 are summarized in Table 5.

\section{Bulk foam stability tests}

Foam was generated by injecting $\mathrm{N}_{2}$ at a rate of $30 \mathrm{cc} / \mathrm{min}$ through the $0.5 \mathrm{wt} \%$ concentration MFOMAX at the bottom of a test tube. The gas injection stopped after foam height reached the peak, and the test countdown began. The bulk foam stability test results performed on three different salinities of $3.5 \mathrm{wt} \%, 2.0 \mathrm{wt} \%$ and $0.5 \mathrm{wt} \%$ are shown in Fig. 4.

The results show that the $2.0 \mathrm{wt} \%$ salinity had the highest foamability since it was able to generate to a maximum volume of approximate $980 \mathrm{ml}$, the medium performer was $0.5 \mathrm{wt} \%$ salinity with a maximum volume of $965 \mathrm{ml}$, and the lowest performer was $3.5 \mathrm{wt} \%$ salinity with a maximum volume of $950 \mathrm{ml}$.

With regard to initial stability, 0.5 and $3.5 \mathrm{wt} \%$ salinities showed stability for only the 5 and $7 \mathrm{~min}$, respectively, but $2 \mathrm{wt} \%$ was stable for up to $10 \mathrm{~min}$, and once the degradation began, the rate of decay was slowest for this salinity, medium for $3.5 \mathrm{wt} \%$ salinity and fastest for $0.5 \mathrm{wt} \%$ salinity.

Regarding long-term stability after $24 \mathrm{~h}$, the $2.0 \mathrm{wt} \%$ salinity again showed the best performance with remaining foam volume of $850 \mathrm{ml}, 3.5 \mathrm{wt} \%$ salinity showed the medium performance with $775 \mathrm{ml}$ remaining volume, and the $0.5 \mathrm{wt} \%$ salinity showed the poorest performance with only $675 \mathrm{ml}$ of volume remaining. The above observations are summarized in Table 6 .

The observations in Table 6 show that the $2.0 \mathrm{wt} \%$ salinity was the best performing solution. However, these rankings are not the same as the one determined by the sandpack flooding experiments, in which $3.5 \mathrm{wt} \%$ salinity performed best, followed closely by $2.0 \mathrm{wt} \%$ salinity. The tests were repeated up to three times, and in all tests the lowest performer identified by both methods was $0.5 \mathrm{wt} \%$ salinity test. Hence, it can be concluded that bulk foam stability tests are not valid for selecting the effect of salinity on foaming performance and therefore should only be used with caution in a way that all closely performing salinities should be evaluated further, but the outlying salinities can be excluded from further evaluation.

\section{Modified bulk foam stability tests}

The modified bulk foam stability tests were performed exactly in the same manner as the standard bulk foam stability test described in section "Bulk Foam Stability Tests" except that 20 grams of quartz river sand was placed at the bottom of the cylinder and the gas was percolated through it to generate more heterogeneous foam. 
Fig. 4 Determination of salinity effect by using the bulk foam stability test

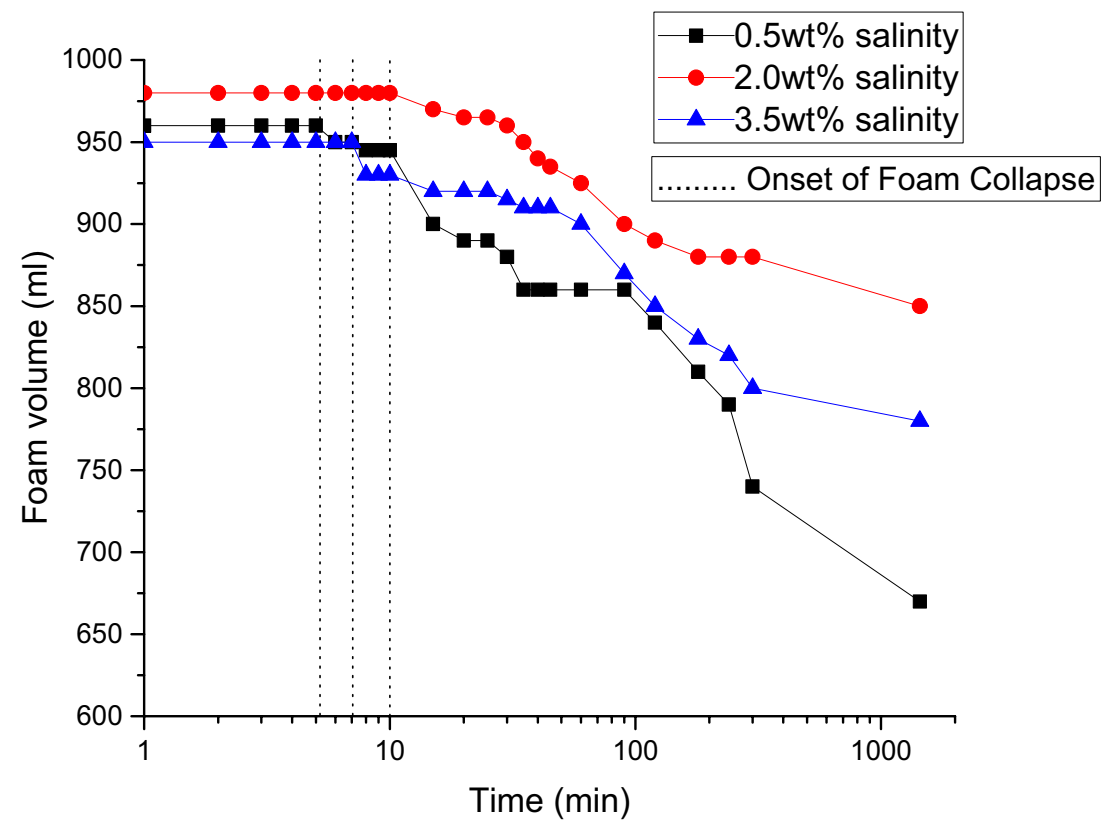

Table 6 Summary of bulk foam stability test result observations for the effect of salinity

\begin{tabular}{llll}
\hline Salinity & $3.5 \mathrm{wt} \%$ & $2.0 \mathrm{wt} \%$ & $0.5 \mathrm{wt} \%$ \\
\hline Peak foam volume & $950 \mathrm{ml}^{\mathrm{b}}$ & $980 \mathrm{ml}^{\mathrm{a}}$ & $965 \mathrm{ml}$ \\
Stable for & $7 \mathrm{~min}$ & $10 \mathrm{~min}^{\mathrm{a}}$ & $5 \mathrm{~min}^{\mathrm{b}}$ \\
Decay behavior & medium & Slowest & fastest \\
Volume after 24 h & $775 \mathrm{ml}$ & $850 \mathrm{ml}^{\mathrm{a}}$ & $675 \mathrm{ml}^{\mathrm{b}}$
\end{tabular}

${ }^{\mathrm{a} B e s t}$ performance, ${ }^{\mathrm{b}}$ lowest performance
The tests were performed at three selected brine salinities as shown in Fig. 5. The results of 2.0 and $3.5 \mathrm{wt} \%$ salinity tests were ambiguous in that it was difficult to decide which one out of the two performed better. Both initially had almost similar performance up to 2 min, after which foam collapsed faster in $2.0 \mathrm{wt} \%$ salinity test as compared to $3.5 \mathrm{wt} \%$ test, but then the trend reversed after $24 \mathrm{~min}$ and the foam collapse was faster in $3.5 \mathrm{wt} \%$ salinity test as compared to $2.0 \mathrm{wt} \%$ test. At the end the performance,
Fig. 5 Determination of salinity effect by using the modified bulk foam stability test

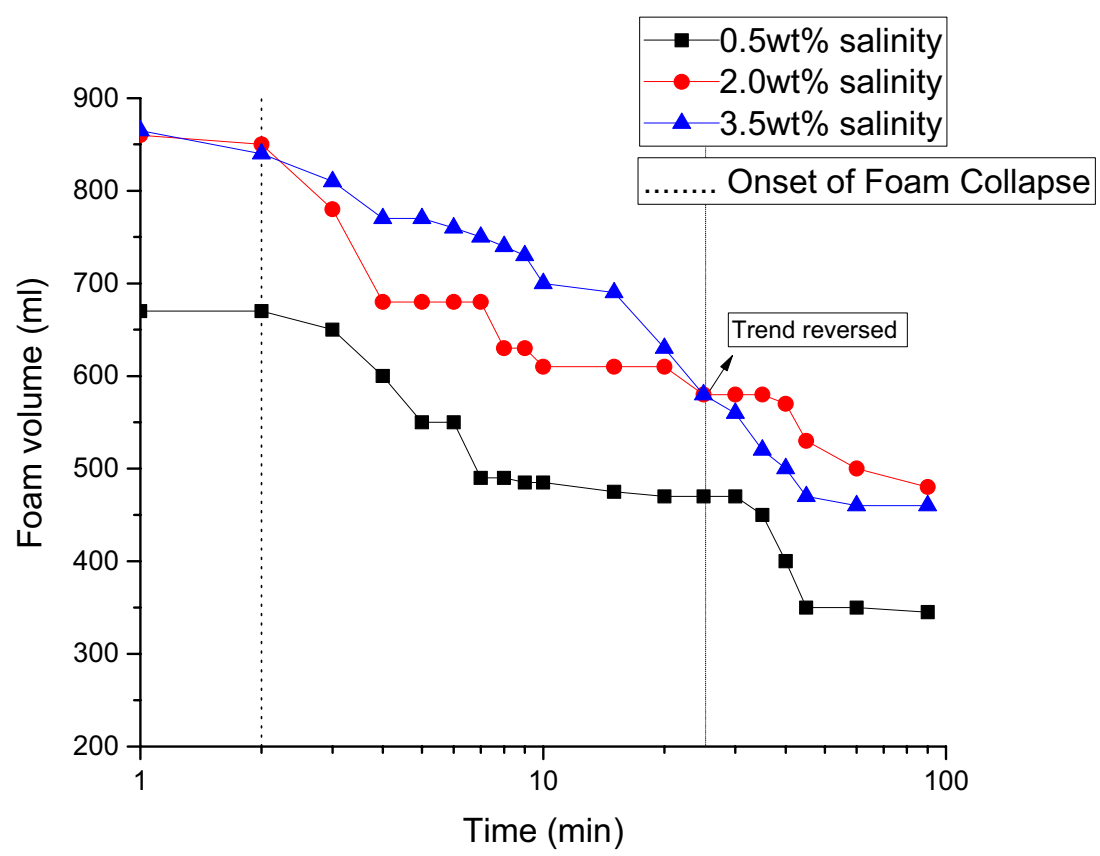

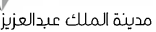
KACST مدينة الملالك عبديز 
gap closed up again and would have come to almost the same level $(470 \mathrm{ml})$ at $110 \mathrm{~min}$ (extrapolated estimation) of elapsed time (gas injection stopping time).

The performance of $0.5 \mathrm{wt} \%$ salinity always trailed significantly compared to the other two higher salinities, and its volume reduced to $350 \mathrm{ml}$ after $90 \mathrm{~min}$, and its degradation behavior was also complex. Table 7 lists the foam heights at several time intervals for the three salinities to help in comparing the performance of the three salinities.

The modified bulk foam stability tests, therefore, suggest that the performance of 2.0 and $3.5 \mathrm{wt} \%$ salinities was varying at intermediate points but had similar ending performance. The $0.5 \mathrm{wt} \%$, however, was the least favorable by a good margin. These rankings are same as the ones determined by the sandpack flooding experiments. However, they differ from the standard bulk foam test with regard to 2.0 and $3.5 \mathrm{wt} \%$ salinities, but do agree for $0.5 \mathrm{wt} \%$ salinity. Hence, it can be concluded that the modified bulk foam stability tests are valid for selecting the brine salinity that is most suitable for a particular application. It is because the presence of sand creates foam of a more heterogenous texture which is more representative of foam in porous media than

Table 7 Summary of the modified bulk foam stability test results for the effect of salinity

\begin{tabular}{llll}
\hline Salinity & $3.5 \mathrm{wt} \%$ & $2.0 \mathrm{wt} \%$ & $0.5 \mathrm{wt} \%$ \\
\hline Peak foam volume & $860 \mathrm{ml}^{\mathrm{a}}$ & $858 \mathrm{ml}$ & $670 \mathrm{ml}^{\mathrm{b}}$ \\
Stable for & Less than 2 min & $2 \mathrm{~min}^{\mathrm{a}}$ & $2 \mathrm{~min}$ \\
Decay behavior & complex & complex & complex \\
Foam volume at 24 min & $580^{\mathrm{a}}$ & $580^{\mathrm{a}}$ & $470^{\mathrm{b}}$ \\
Foam volume at 90 min & $470 \mathrm{ml}$ & $475 \mathrm{ml}^{*}$ & $350 \mathrm{ml}^{\mathrm{b}}$ \\
\hline
\end{tabular}

${ }^{\mathrm{a} B}$ Best performance, ${ }^{\mathrm{b}}$ lowest performance the uniform foam texture created in the standard bulk foam stability tests that have no sand.

\section{Effect of surfactant concentration}

In the previous section, the bulk and modified bulk foam stability tests were performed at three selected brine salinities of $3.5 \mathrm{wt} \%, 2.0 \mathrm{wt} \%$ and $0.5 \mathrm{wt} \%$, and their performance was ranked and compared with the ranking obtained by the sandpack flooding tests. In this section, the effect of surfactant concentration similarly examined using MFOMAX at fixed salinity of $2.0 \mathrm{wt} \%$ and three different surfactant concentration as $0.1,0.5$ and $1 \mathrm{wt} \%$. All the tests performed at similar operating conditions as mentioned in Table 4 except the surfactant concentration which was the variable in this set of experiments.

\section{Sandpack flood tests}

Same as the previous section, unsteady-state surfactant solution drainage by $\mathrm{N}_{2}$ injection performed for three solutions of different surfactant concentrations at fixed salinity. Before each test, the sandpack was cleaned, dried, evacuated and fully saturated with brine; which was then displaced by MFOMAX solution of variable concentration. Pressure drop was noted starting from $\mathrm{N}_{2}$ gas injection.

Figure 6 shows that the foaming started earliest in case of $1.0 \mathrm{wt} \%$ surfactant concentration (after 1.0 PV injection). In the case of $0.5 \mathrm{wt} \%$ and $0.1 \mathrm{wt} \%$ concentrations, the onset of foaming was delayed till 1.2 PV and 1.15 PV injections, respectively.

The peak pressure drop (DP) was 6.5 psig in case of 1.0 wt $\%$ concentration, and a close value of $5.5 \mathrm{psig}$ for $0.5 \mathrm{wt} \%$
Fig. 6 Determination of the effect of surfactant concentration by sandpack using the unsteady-state surfactant drainage by gas injection

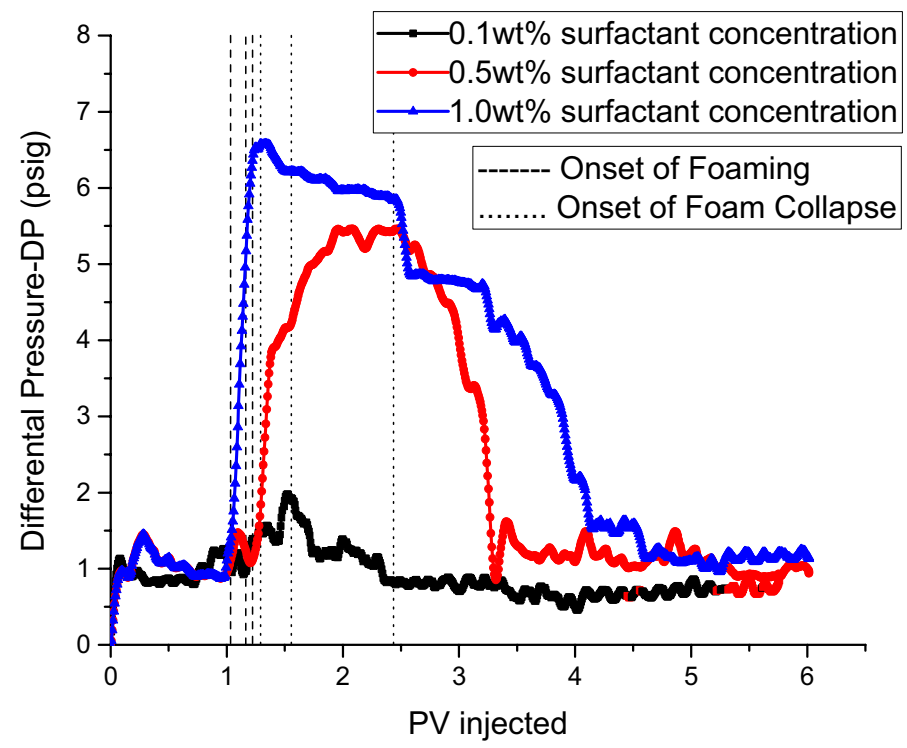


concentration, whereas it only reached up to $2.0 \mathrm{psig}$ in case of $0.1 \mathrm{wt} \%$ concentration.

The foam started collapsing earliest (at 1.25 PV) and collapsed completely after 4.5 PV gas injection in case of $1.0 \mathrm{wt} \%$ surfactant concentration. The collapse was more delayed (2.4 PV) in $0.5 \mathrm{wt} \%$ concentration, but the foam completely collapsed very fast after 3.3 PV. In the case of $0.1 \mathrm{wt} \%$ concentration, foam collapse started relatively earlier (1.6 PV) and entirely collapsed by $2.4 \mathrm{PV}$ of injection. The key observations of the three tests are listed in Table 8.

Overall, the performance of $1.0 \mathrm{wt} \%$ concentration was the best, but $0.5 \mathrm{wt} \%$ was a very close runner-up. However, the behavior of $0.1 \mathrm{wt} \%$ concentration test was drastically different, and its performance was very poor as compared to the other two.

In conclusion, the sandpack flood test revealed that the $1.0 \mathrm{wt} \%$ concentration performed best, followed closely by $0.5 \mathrm{wt} \%$ concentration, and the lowest performer was the 0.1 wt $\%$ concentration.

Table 8 Summary of sandpack flood result for the effect of surfactant concentration

\begin{tabular}{llll}
\hline Surfactant Conc. & $1.0 \mathrm{wt} \%$ & $0.5 \mathrm{wt} \%$ & $0.1 \mathrm{wt} \%$ \\
\hline Onset of foaming & $1.0 \mathrm{PV}$ & $1.25 \mathrm{PV}$ & $1.15 \mathrm{PV}$ \\
Peak DP & $6.5 \mathrm{psig}$ & $5.5 \mathrm{psig}$ & $2.0 \mathrm{psig}$ \\
The onset of foam collapse & $1.25 \mathrm{PV}$ & $2.4 \mathrm{PV}$ & $1.6 \mathrm{PV}$ \\
Total PV which DP drop from & $3.25 \mathrm{PV}$ & $0.9 \mathrm{PV}$ & $0.8 \mathrm{PV}$ \\
$\quad$ peak to valley & & & \\
DP at the valley & $1.0 \mathrm{psig}$ & $0.9 \mathrm{psig}$ & $0.8 \mathrm{psig}$ \\
\hline
\end{tabular}

\section{Bulk foam stability tests}

To compare the surfactant concentration screening performance with sandpack, the bulk foam stability tests were performed in exactly the similar manner as for the bulk foam stability tests described earlier except that the salinity was fixed this time but MFOMAX surfactant concentration varied. The bulk foam stability test results performed on three different surfactant concentrations of $1.0 \mathrm{wt} \%, 0.5 \mathrm{wt} \%$ and $0.1 \mathrm{wt} \%$ at fixed salinity of $2 \mathrm{wt} \%$ are shown in Fig. 7.

The results in Fig. 7 show that the 1.0 and 0.5 wt\% surfactant concentration had the highest foamability since they were both able to generate foam to an approximate maximum volume of $990 \mathrm{ml}$. On contrary, the $0.1 \mathrm{wt} \%$ surfactant concentration showed that a distantly lower performance was able to generate foam to a maximum volume of $320 \mathrm{ml}$ only.

The $1.0 \mathrm{wt} \%$ and $0.5 \mathrm{wt} \%$ surfactant concentrations both had similar initial stability for first $30 \mathrm{~min}$, whereas the stability of $0.5 \mathrm{wt} \%$ surfactant concentration was much lower at only $10 \mathrm{~min}$.

Once the degradation began, the rate of decay was slowest for $1.0 \mathrm{wt} \%$ surfactant concentration, whereas $0.5 \mathrm{wt} \%$ surfactant concentration was a close runner-up with only slightly faster decay. The $0.1 \mathrm{wt} \%$ surfactant concentration, however, had much faster decay.

In terms of long-term stability after $24 \mathrm{~h}$, the $1.0 \mathrm{wt} \%$ surfactant concentration showed the best performance with remaining foam volume of $890 \mathrm{ml}$, and $0.5 \mathrm{wt} \%$ surfactant concentration showed only slightly lower performance with $850 \mathrm{ml}$ remaining volume, but the $0.1 \mathrm{wt} \%$ surfactant concentration showed drastically poorer performance with just
Fig. 7 Determination of the effect of surfactant concentration by bulk foam stability test

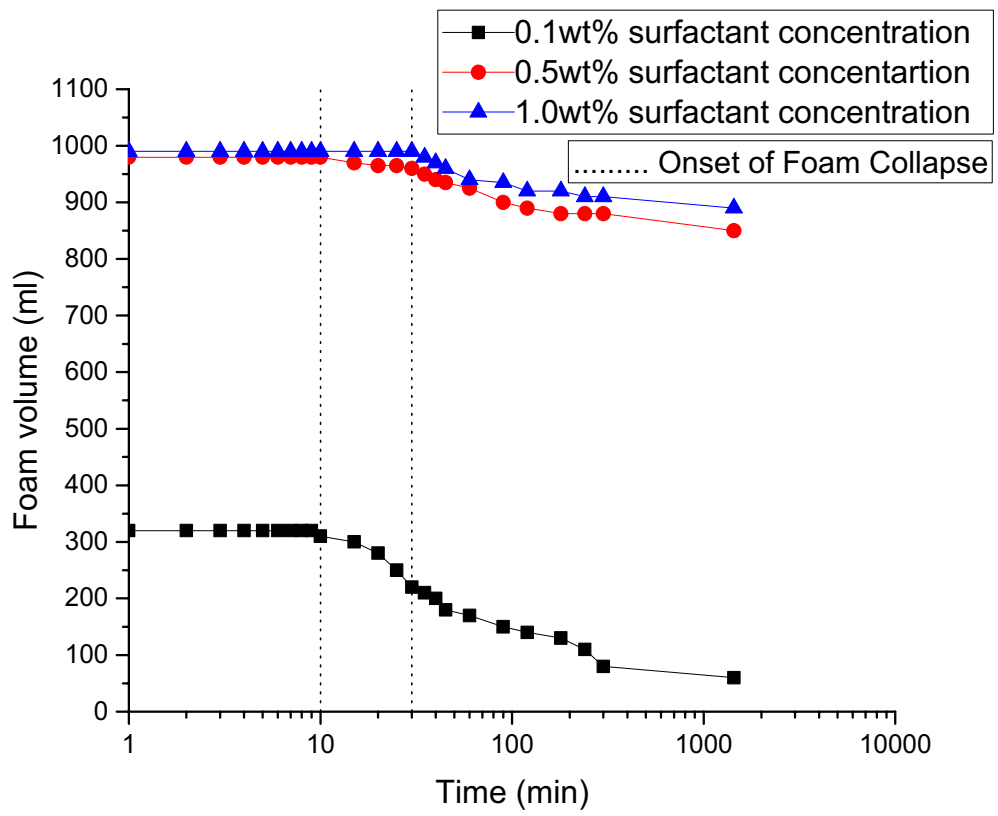

Time (min) 
$55 \mathrm{ml}$ of volume remaining. The above observations are summarized in Table 9.

These rankings are the same as the one determined by the sandpack flooding experiments, in which $1.0 \mathrm{wt} \%$ surfactant concentration performed best, followed closely by $0.5 \mathrm{wt} \%$ surfactant concentration. The lowest performer identified by both methods was $0.1 \mathrm{wt} \%$ surfactant concentration tests. Hence, it can be concluded that bulk foam stability tests are valid for determining the effect of surfactant concentration on foaming performance.

\section{Modified bulk foam stability tests}

To compare the surfactant concentration screening performance with sandpack, the modified bulk foam stability tests were performed in exactly the similar manner as for the modified bulk foam stability tests in previous set of experiments except that the salinity was fixed this time but MFOMAX surfactant concentration varied.

Table 9 Summary of bulk foam stability test results for the effect of surfactant concentration

\begin{tabular}{llll}
\hline Surfactant Conc. & $1.0 \mathrm{wt} \%$ & $0.5 \mathrm{wt} \%$ & $0.1 \mathrm{wt} \%$ \\
\hline Peak foam volume & $990 \mathrm{ml}^{\mathrm{a}}$ & $990 \mathrm{ml}^{\mathrm{a}}$ & $320 \mathrm{ml}^{\mathrm{b}}$ \\
Stable for & $30 \mathrm{~min}^{\mathrm{a}}$ & $30 \mathrm{~min}^{\mathrm{a}}$ & $10 \mathrm{~min}^{\mathrm{b}}$ \\
Decay behavior & slowest & Slow & fastest \\
Volume after 24 h & $890 \mathrm{ml}^{\mathrm{a}}$ & $850 \mathrm{ml}$ & $55 \mathrm{ml}^{\mathrm{b}}$ \\
\hline
\end{tabular}

${ }^{\mathrm{a} B e s t}$ performance, ${ }^{\mathrm{b}}$ lowest performance
Figure 8 shows the test results of modified bulk foam stability tests performed on three selected surfactant concentrations.

Figure 8 shows that $1.0 \mathrm{wt} \%$ surfactant concentration had a complex degradation behavior but showed the highest stability since its foam volume was still $515 \mathrm{ml}$ after $90 \mathrm{~min}$ of elapsed time (gas injection stopping time). The stability of $0.5 \mathrm{wt} \%$ surfactant concentration was trailing the $1.0 \mathrm{wt} \%$ surfactant concentration perhaps because it started decaying almost immediately and showed steady pace degradation behavior, but it caught up at the end eventually retaining $475 \mathrm{ml}$ after $90 \mathrm{~min}$ of elapsed time.

The degradation behavior of $0.1 \mathrm{wt} \%$ of surfactant concentration was similar to the $1 \mathrm{wt} \%$ of surfactant concentration regarding the shape of the decay curve. However, the curve significantly trailed the other two surfactant concentrations since the starting volume was much smaller $(325 \mathrm{ml})$ then the other two. The remaining foam volume was only $70 \mathrm{ml}$ after $90 \mathrm{~min}$ of elapsed time. The key observations of the test are listed in Table 10.

The $1.0 \mathrm{wt} \%$ surfactant concentration generated the most stable foam as it was able to retain a PV of 515 after $90 \mathrm{~min}$, the close runner-up was $0.5 \mathrm{wt} \%$ surfactant concentration at $475 \mathrm{ml}$, and the lowest performer by a significant margin was $0.1 \mathrm{wt} \%$ surfactant concentration with only $70 \mathrm{ml}$.

The results suggest that $1.0 \mathrm{wt} \%$ surfactant concentration was the best performer, after that $0.5 \mathrm{wt} \%$ surfactant concentration and the $0.1 \mathrm{wt} \%$ surfactant concentration were the least favorable. These rankings are the same as the one determined by the sandpack flooding experiments. Hence, it can be concluded that the modified bulk foam
Fig. 8 Determination of the effect of surfactant concentration by modified bulk foam stability test

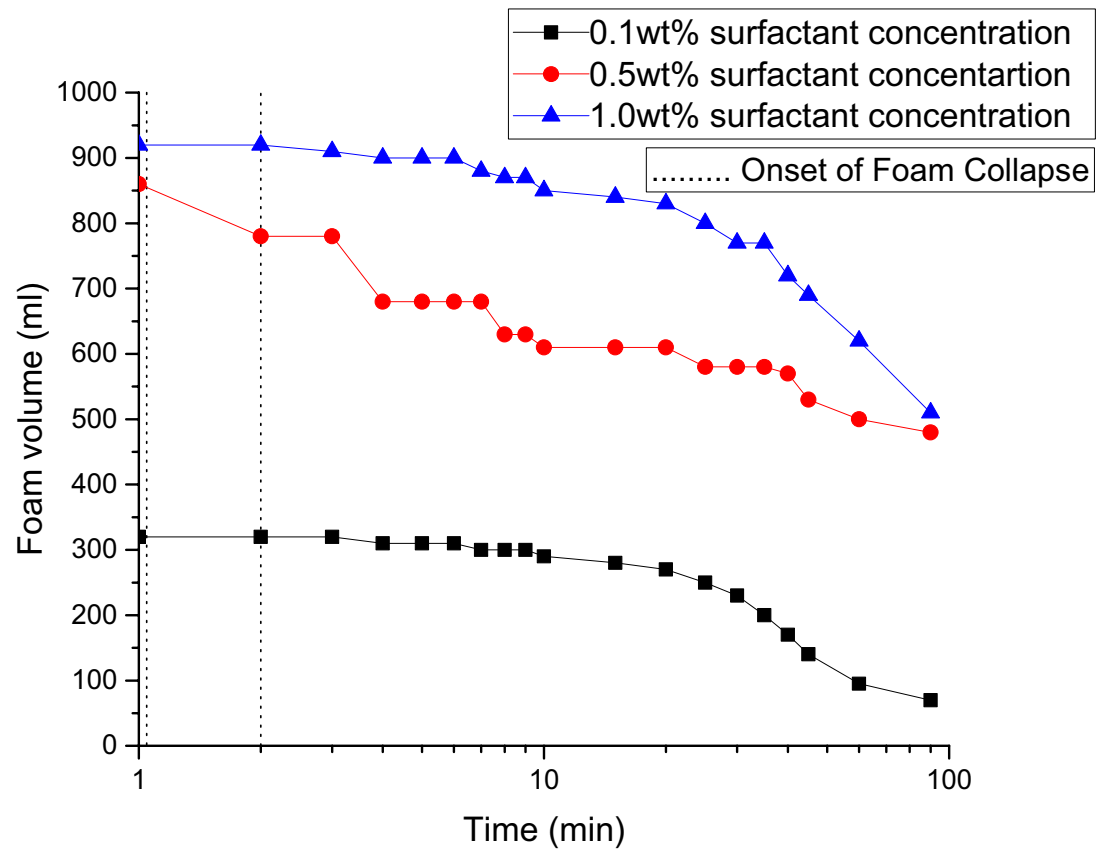


Table 10 Summary of modified bulk foam stability test for the effect of surfactant concentration

\begin{tabular}{llll}
\hline Surfactant Conc. & $1.0 \mathrm{wt} \%$ & $0.5 \mathrm{wt} \%$ & $0.1 \mathrm{wt} \%$ \\
\hline Peak foam volume & $920 \mathrm{ml}^{\mathrm{a}}$ & $860 \mathrm{ml}$ & $320 \mathrm{ml}^{\mathrm{b}}$ \\
Stable for & $2 \mathrm{~min}^{\mathrm{a}}$ & $0.2 \mathrm{~min}^{\mathrm{b}}$ & $2 \mathrm{~min}^{\mathrm{a}}$ \\
Decay behavior & Complex & Almost Linear & Complex \\
Volume after $90 \mathrm{~min}$ & $515 \mathrm{ml}^{\mathrm{a}}$ & $475 \mathrm{ml}$ & $70 \mathrm{ml}^{\mathrm{b}}$ \\
\hline
\end{tabular}

${ }^{\mathrm{a}}$ Best performance, ${ }^{\mathrm{b}}$ lowest performance

stability tests appear to be valid to screen the effect of surfactant concentration on both foamability and foam stability.

In addition, it can be seen that modified bulk foam stability tests were able to discern between the $0.5 \mathrm{wt} \%$ and 1.0 $\mathrm{wt} \%$ performance more proportionately with the sandpack tests as compared to the standard bulk foam stability tests in which $0.5 \mathrm{wt} \%$ and $1.0 \mathrm{wt} \%$ performance was almost similar as opposed to the sandpack tests.

\section{Conclusions}

The foam generated in bulk foam stability test was observed to be quite homogeneous, while foam through porous media is more heterogeneous, though a modification to the bulk foam test is proposed by adding small quantity of quartz river sand at the bottom of the test tube for generating foam that simulates porous media.

By comparing the foam stability observations through bulk, modified bulk and sandpack flooding tests, the following conclusion can be drawn:

- All three screening methods yield compatible results for screening the effect of surfactant concentration on foaming performance.

- Standard bulk foam stability tests yielded differing screening results as compared to the other two screening methods for the effect of salinity on foaming performance. However, they may still be used to screen out very low performers.

- Modified bulk foam stability tests were able to yield screening results similar to the sandpack tests. In addition, their relative performance was more proportionately matching with the sandpack tests as compared to the standard bulk foam stability tests. It is perhaps because the presence of sand helped to create foam of more heterogenous texture than in the standard bulk foam stability tests.
Acknowledgement The authors gratefully acknowledge the financial support from the Shell-TU Delft-UTP collaborative project under Grant No: 0153AB-DA2. The research was conducted at the COREOR center of University Teknologi PETRONAS.

Open Access This article is distributed under the terms of the Creative Commons Attribution 4.0 International License (http://creativeco mmons.org/licenses/by/4.0/), which permits unrestricted use, distribution, and reproduction in any medium, provided you give appropriate credit to the original author(s) and the source, provide a link to the Creative Commons license, and indicate if changes were made.

\section{References}

Agneta M, Zhaomin L, Chao Z, Gerald G (2019) Investigating synergism and antagonism of binary mixed surfactants for foam efficiency optimization in high salinity. J Pet Sci Eng 175:489-494

Akbari S, Mahmood SM, Tan IM, Ghaedi H, Ling OL (2017a) Assessment of polyacrylamide based Co-polymers enhanced by functional group modifications with regards to salinity and hardness. Polymers 9:647

Akbari S, Mahmood SM, Tan IM, Ghaedi H, Ling OL (2017b) Effect of aging, antioxidant, and mono- and divalent ions at high temperature on the rheology of new polyacrylamide-based co-polymers. Polymers 9:480

Andrianov A, Farajzadeh R, Mahmoodi Nick M, Talanana M, Zitha PLJ (2012) Immiscible foam for enhancing oil recovery: bulk and porous media experiments. Ind Eng. Chem Res 51(5):2214-2226

Apaydin OG, Kovscek AR (2001) Surfactant concentration and end effects on foam flow in porous media. Transp Porous Media 43(3):511-536

Aronson AS, Bergeron V, Fagan ME, Radke CJ (1994) The influence of disjoining pressure on foam stability and flow in porous media. Colloids Surfaces A Physicochem Eng Asp 83(2):109-120

Bergeron V, Fagan ME, Radke CJ (1993) Generalized entering coefficients: a criterion for foam stability against oil in porous media. Langmuir 9(7):1704-1713

Bond DC, Holbrook OC (1958) Gas drive oil recovery process. U.S. Patent 2866507

Dong P, Puerto M, Ma K, Mateen K, Ren G, Bourdarot G, Hirasaki G (2018) Ultralow-interfacial-tension foam injection strategy investigation in high temperature ultra-high salinity fractured carbonate reservoirs. In: SPE improved oil recovery conference, 14-18 April, Tulsa, Oklahoma, USA. Society of Petroleum Engineers. https://doi.org/10.2118/190259-MS

Falls AH, Musters JJ, Ratulowski J (1989) The apparent viscosity of foams in homogeneous bead packs. SPE Reserv Eng 4(May): $155-164$

Farajzadeh R, Andrianov A, Bruining H, Zitha PLJ (2009) Comparative study of $\mathrm{CO}_{2}$ and $\mathrm{N}_{2}$ foams in porous media at low and high pressure-temperatures. Ind Eng Chem Res 48(9):4542-4552

Farajzadeh R, Andrianov A, Zitha PLJ (2010) Investigation of immiscible and miscible foam for enhancing oil recovery. Ind Eng Chem Res 49(4): 1910-1919

Farzaneh SA, Sohrabi M (2013) A review of the status of foam application in enhanced oil recovery. In: SPE-164917-MS, Present. EAGE annual conference and exhibition Inc. SPE European 10-13 June, London, UK, pp 1-15

Fergui O, Bertin H, Quintard M (1998) Transient aqueous foam flow in porous media: experiments and modeling. J Pet Sci Eng 20(1-2):9-29 
Fukami T, Chen R-H (1998) Crystal structure and electrical conductivity of LiN2H5SO4 at high temperature. Jpn J Appl Phys 37(3A):925-929

Hadian N, Syed N, Hamed MM (2019) A rigorous approach to analyze bulk and coreflood foam screening tests. J Pet Explor Prod Technol 9(2):809-822

Huh C (1979) Interfacial tensions and solubilizing ability of a microemulsion phase that coexists with oil and brine. J Colloid Interface Sci 71(2):408-426

Jones SA, van der Bent V, Farajzadeh R, Rossen WR (2015) Small core flood experiments for foam EOR-screening surfactant applications TU delft shell global solution international aqueous foams are a means of increasing the sweep efficiency of enhanced oil recovery processes. An understanding of how a foam beh," no, pp 14-16

Khatib ZI, Hirasaki GJ, Falls AH (1988) Effects of capillary pressure on coalescence and phase mobilities in foams flowing through porous media. SPE Reserv Eng 3(03):919-926

Kristiansen TS, Holt T (1992) Properties of flowing foam in porous media containing oil. In: SPE/DOE enhanced oil recovery symposium, pp 279-287

Liu Y, Grigg RB, Bai B (2005) Salinity, pH, and surfactant concentration effects on $\mathrm{CO}_{2}$-foam. In: SPE international symposium on oilfield chemistry, pp 1-11

Ma K, Lopez-Salinas JL, Puerto MC, Miller CA, Biswal SL, Hirasaki GJ (2013) Estimation of parameters for the simulation of foam flow through porous media. Part 1: the dry-out effect. Energy Fuels 27(5):2363-2375

Mannhardt K, Novosad J, Schramm L (2000) Comparative evaluation of foam stability to oil. SPE Reserv Eval Eng 3(1):19-22

Namani M, Kleppe J, Høier L, Karimaie H, Torsæter O (2012) Analytical model for zones distributions in non-horizontal miscible wag injection. Energy Environ Res 2(2):159-167
Osei-bonsu K, Shokri N, Grassia P (2015) Colloids and surfaces a: physicochemical and engineering aspects foam stability in the presence and absence of hydrocarbons: from bubble- to bulkscale. Colloids Surfaces A Physicochem Eng Asp 481:514-526

Salager J, Marquez N, Graciaa A, Lachaise J (2000) Microemulsion-oil-water systems : influence of temperature and relation between partitioning coefficient and physicochemical formulation. Langmuir 16(14):5534-5539

Torrealba V, Johns RT (2017) Coupled interfacial tension and phase behavior model based on micellar curvatures coupled interfacial tension and phase behavior model based on micellar curvatures. Langmuir 33:13604-13614

Torrealba VA, Johns RT (2018) Partition-coefficient relations for improved equation-of-state description of microemulsion-phase behavior. SPE J 23:1899-1908. https://doi.org/10.2118/17984 5-PA

van der Bent VJ (2014) AES/PE/14-24 comparative study of foam stability in bulk and porous media

Varade SR, Ghosh P (2017) Foaming in aqueous solutions of zwitterionic surfactant: effects of oil and salts. J Dispers Sci Technol 2691:1770-1784

Vikingstad AK, Aarra MG (2009) Comparing the static and dynamic foam properties of a fluorinated and an alpha olefin sulfonate surfactant. J Pet Sci Eng 65(1-2):105-111

Publisher's Note Springer Nature remains neutral with regard to jurisdictional claims in published maps and institutional affiliations. 